\title{
More than one type of transglutaminase in invertebrates? A second type of transglutaminase is involved in shrimp coagulation
}

\author{
Meng-Yi Chen ${ }^{\mathrm{a}}$, Kuang-Yu Hu ${ }^{\mathrm{b}}$, Chih-Cheng Huang ${ }^{\mathrm{a}}$, Yen-Ling Song ${ }^{\mathrm{a}, \mathrm{c}, *}$ \\ ${ }^{a}$ Institute of Zoology, National Taiwan University, Taipei 106, Taiwan \\ ${ }^{\mathrm{b}}$ Department of Biochemistry, National Defense Medical Center, National Defense University \\ ${ }^{\mathrm{c}}$ Department of Life Science, National Taiwan University, Taipei 106, Taiwan
}

Received 25 January 2005; revised 25 March 2005; accepted 31 March 2005

Available online 23 May 2005

\begin{abstract}
Coagulation (clot formation) forms a physical barrier to prevent the loss of body fluid and dissemination of microbes into the haemocoel after injury or infection. Its quickness and efficiency are essential for the survival of invertebrates that rely solely on innate immunity. Transglutaminase (TG) catalyses intermolecular or intramolecular $\varepsilon$ - $(\gamma$-glutamyl) lysine bond formation, resulting in a protein polymerisation, and plays a role in blood coagulation and post-translational protein remodelling. In the present study, we cloned a TG from shrimp (Penaeus monodon) haemocyte cDNA. It was assigned as shrimp transglutaminase II (STG II). The STG II cDNA consists of a coding region of 2,274 bp. The deduced protein has 757 amino acid residues with a calculated molecular mass of 85,000 Da and an isoelectric point of 5.48. RT-PCR results showed a significant level of STG II expression in haemocytes but not in hepatopancreas, in contrast to shrimp STG I (AY074924.1). The genetic distance between STG II and STG I is much larger than the distance between STG II and the TG of the kuruma shrimp (Marsupenaeus japonicus). Evidence based on tissue distribution and genetic distance suggests that no less than two types of shrimp TG exist that are encoded at different chromosomal locations. The recombinant STG II (rSTG II) incorporated a TG-specific substrate, dansylcadaverine (DCA), into clottable proteins (CP) in a calcium dependent manner. Other haemocyte- or plasma-derived TG substrate is not required for CP polymerisation but may be necessary for stable clot formation. The rSTG II catalysed clottable proteins into a long chain under transmission electron microscopy (TEM) observation. In conclusion, STG II is characterized as a haemocyte TG and is involved in coagulation.
\end{abstract}

(C) 2005 Elsevier Ltd. All rights reserved.

Keywords: Invertebrate; Transglutaminase; Clottable protein; Clotting; Coagulation

\footnotetext{
Abbreviations TG, transglutaminase; STG, shrimp TG; CP, clottable protein; HLS, haemocyte lysate supernatant; DCA, dansylcadaverine.

* Corresponding author. Address: Institute of Zoology, National Taiwan University, Taipei 106, Taiwan. Tel.: +88623366 2455; fax: +886223660243 .

E-mail address: song@ntu.edu.tw (Y.-L. Song).
}

\section{Introduction}

Coagulation or clot formation is one of the most important innate immune responses. Its quickness and efficiency in forming a physical barrier to avoid the loss of body fluid and prevent the dissemination of microbes into the haemocoel in invertebrates is 
necessary to survival [1-3]. The diversity of coagulation systems reflects the heterogeneity of invertebrates. However, transglutaminase (TG) (EC 2.3.2.13) is the only element which is conserved in the coagulation systems of all known invertebrate species [4-9]. TG is a ubiquitous enzyme catalysing acyl transfer between the $\varepsilon$-amino group of a peptidebound lysine or the primary amino group of a polyamine and the $\gamma$-carboxamide group of a peptide-bound glutamine. When a protein-bound lysine residue acts as an acyl acceptor, intermolecular or intramolecular $\varepsilon$ - $(\gamma$-glutamyl) lysine bonds form, resulting in protein polymerisation [10-13]. The TGs are known primarily for their roles in blood coagulation and post-translational protein remodelling.

In mammals, nine TGs have been characterized based primarily on their gene loci on chromosomes and partly on their tissue distributions and functions [14]. A number of post-translational modifications, including phosphorylation, fatty acylation, and proteolytic cleavage regulate their enzymatic activity and subcellular localization [15-17]. Blood coagulation factor XIIIa (F. XIIIa) catalyses the cross-linking of fibrin monomers, which is the last step in blood coagulation [18]. F. XIIIa significantly increases clot strength and shortens bleeding time [19]. A lack of F. XIIIa impairs clot firmness, probably due to reduced cross-linking. An application of F. XIIIa might be useful in increasing clot firmness in patients who are at risk during an intraoperative coagulopathy [20]. Recently, a F. XIIIa-like embryonic transglutaminase found in fish was identified as playing a role in the early vascular development of vertebrates [21], suggesting a function other than coagulation. Both TG1 (keratinocyte TG) and TG 3 (epidermal TG) help maintain skin epidermis and hair follicle epithelium intactness by cross-linking structural proteins $[22,23]$. TG2 (tissue TG) has been implicated in apoptosis, and in the formation and stabilization of the extracellular matrix. In certain signal transduction pathways, TG2 acts as a GTP-binding protein, $\mathrm{G}_{\mathrm{h}}$ [24,25], that is involved in erythrocyte differentiation [26]. TG4 ( $\mathrm{TG}_{\mathrm{P}}$ found in the prostate) is essential for semen coagulation in rodents [27]. Human TGs 5, 6 and 7 have been discovered recently and their function is still unknown [14]. One TG homologue (erythrocyte membrane protein band 4.2) with mutated catalytic triads is a major component of the red blood cell membrane skeleton. A deficiency of protein band 4.2 is linked with a variety of hereditary haemolytic anaemias [28-32].

In invertebrates, TGs from the crayfish [9], the horseshoe crab [4,33,34], the grasshopper [35], the starfish [36], the fruit fly [37], the tiger shrimp [38] and the malaria mosquito [39] have been identified. In insects such as fruit flies and mosquitoes whose genomes were sequenced, only one locus encoding TG with a functional domain organization was identified and thus implied multiple functions. However, there is still no direct evidence suggesting the functions of insect TG. In starfish and grasshoppers, TG has a role in embryonic development, which requires extensive extracellular matrix remodelling. Among the invertebrates, although it has been suggested that clotting activity is dependent upon the TG activity in haemocytes [40-43], the horseshoe crab TG is the first one for which an involvement in coagulation was demonstrated by purified recombinant protein. The horseshoe crab TG and its substrate in coagulation (proxin) are both located in haemocytes. The activation of horseshoe crab coagulation begins by an initiation of lipopolysaccharide or $\beta$ 1,3 -glucan recognition that triggers a series of protease cascades to cleave zymogen and proprotein, in a way similar to the signal amplification cascade in mammalian coagulation activation [44-48].

In regard to insects, genomic and proteomic data show that, with the exception of transglutaminase, few orthologues can be identified amongst the coagulation factors of mammals, horseshoe crabs and shrimps $[7,8]$.

In shrimps, coagulation is initiated by the activation and lysis of hyaline cells (deposit cells), which release haemocyte components to react with plasma factors [42]. The haemocyte component is believed to be a transglutaminase $[5,6]$. The plasma factor has been purified and is known as clottable protein $(\mathrm{CP})$ in tiger shrimps [5]. Tiger shrimp $\mathrm{CP}$ resembles the Vitellogenin family clotting protein in crayfish [6]. A tiger shrimp (Penaeus monodon) transglutaminase has been cloned from the haemocyte, but no clotting activity was detected [38]. In the present study, we cloned a second TG from the tiger shrimp haemocyte cDNA. It was assigned as shrimp transglutaminase II (STG II) to differentiate it from the previous one 
(STG I). Genetic distance and tissue distribution suggest the existence of at least two types of shrimp TG encoded by different chromosomal loci. STG II was characterized as a haemocyte TG that is involved in coagulation.

Moreover, the coagulation system seems to be a target in virus attacks. In shrimps infected with the Taura syndrome virus, transglutaminase activity declines concomitantly [49]. A more detailed understanding of shrimp transglutaminase and clotting regulation is therefore not only a good scientific research area but will make a significant contribution to the control of diseases that affect the aquaculture of invertebrates.

\section{Materials and methods}

\subsection{Haemocyte cDNA preparation and cloning of $S T G$ II open reading frame (ORF)}

Shrimp hemolymph was withdrawn using a syringe containing anticoagulant $(0.1 \mathrm{M}$ sodium citrate, $0.4 \mathrm{M}$ sucrose, $0.01 \mathrm{M}$ Tris- $\mathrm{HCl}, \mathrm{pH} 7.6,780 \mathrm{mOsm} / \mathrm{kg}$ ) and centrifuged at $700 \mathrm{~g}$ for $10 \mathrm{~min}$ to collect haemocytes. Total RNA was extracted and cDNA was synthesized using the SuperScript ${ }^{\mathrm{TM}}$ III FirstStrand Synthesis System for RT-PCR (Invitrogen, USA). The primers (5'-ATGTCGTTCTTCAGTTCCTT-3' (forward) and 5'-TCACTCTGCCGGATTGATGG- $3^{\prime}$ (reverse)) were designed based on the sequence of AF469484 (also an STG). The annealing temperature was $52{ }^{\circ} \mathrm{C}$ and the annealing time was set to $40 \mathrm{~s}$. The $2-2.5 \mathrm{kbp}$ PCR product was ligated to a pGEMT-easy vector (Promega, USA), transformed to E. coli DH5 $\alpha$ and screened with ampicillin and X-gal colorization. The sequence was determined (by Mission Biotech Inc., Taiwan) to ensure that it contained the expected transglutaminase open reading frame.

\subsection{Sequence analysis and comparison}

Putative motifs and domains were detected using Motif Scan [50] at www.expasy.org. Related sequences were searched using BLASTP 2.2.9 and PSI-BLAST [51] at the National Center for Biotechnology Information (NCBI) and multiple-aligned using ClustalX [52]. Phylogenetic and molecular evolutionary analyses were conducted using the maximum parsimony method of MEGA version 2.1 [53].

\subsection{Tissue distribution of shrimp clotting enzyme by $R T$-PCR}

Total RNA was extracted from a variety of shrimp tissues, including the eyestalk, intestine, hepatopancreas, gills, heart, lymphoid organ, sub-cuticular epithelium and haemocytes. A 407-bp fragment of STG II was amplified by RT-PCR using oligonucleotides $5^{\prime}$-CCGTCTCATGTCCCAAGGAG-3' (forward) and $5^{\prime}$-CCGCAGTGGCCTCCGACAGG-3' (reverse). The primer set was designed to distinguish STG I and STG II, but not the two isoforms of STG II. The specificity is justified by blast search of the two short primer sequences against the non-redundant database of NCBI. The blast result contains two isoforms of STG II but no STG I. The predicted product size is exactly $407 \mathrm{bp}$. The location of the primer has been indicated by arrows in Fig. 1 (the forward primer starts from the location 1605 and the reverse primer starts from the location 2011 in the reverse direction).

\subsection{Expression and purification of recombinant STG II}

Another pair of primers was designed to contain the start and stop codon of the expected TG ORF with a restriction site sequence of $S a c I$ and $P a c$ I respectively for further cloning. On the PacI primer, the nucleotide encoding 6xHis was added before the stop codon to encode the C-terminal His tag used in the subsequent purification process. The ORF was PCR amplified with the primer containing restriction site and 6xHis tag, cloned in transfer vector $\mathrm{pABhRpX}$ and sequenced again. The recombinant STG II-pABhRpx containing an HSP70 promoter to express the DsRed fluorescent marker and a polyhedrin promoter to express the insert gene was used to co-transfect monolayered Spodoptera frugiperda insect cells $(S f 21)$ with linearized AcMNPV to generate recombinant STG II-AcMNPV. The recombinant STG II-AcMNPV was used to transfect monolayered Sf21 cells to produce rSTG II. The $S f 21$ cells were harvested by centrifugation and lysed 
1 atgtcgttet tcagt tcet tegagaat t tectggacaacct gaccgaccgct tcaggcatgacet cgaggt caaccgcegegaggacagg

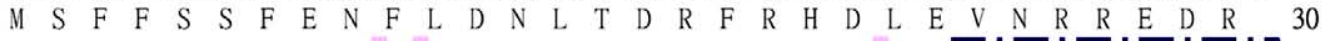

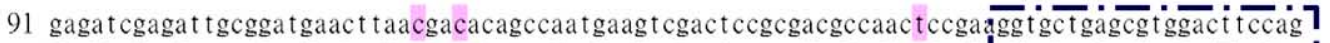

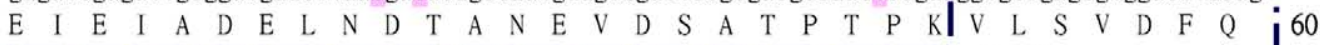

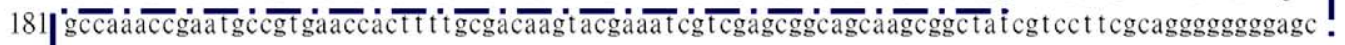
\begin{tabular}{lllllllllllllllllllllllllllllll|l}
$-A$ & $K$ & $P$ & $N$ & $A$ & $V$ & $N$ & $H$ & $F$ & $C$ & $D$ & $K$ & $Y$ & $E$ & $I$ & $V$ & $E$ & $R$ & $Q$ & $Q$ & $A$ & $A$ & $I$ & $V$ & L & $R$ & $R$ & $G$ & $G$ & $S$ & 90
\end{tabular}

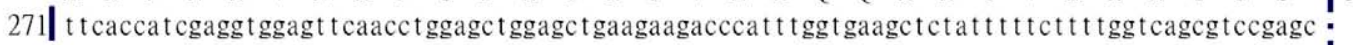

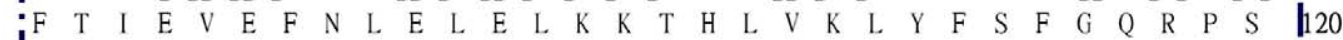
${ }_{361}$ gcggcgaagggaacccaggctgccet t caggt at cgggcaagaaact t t tcgacaagaaccacgaggagt gggacgt gcgegt ggacggg

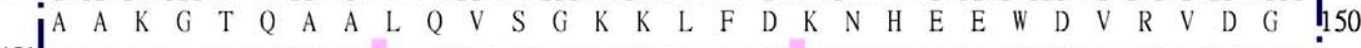
451. caaaacggcaagaaaa t cacct tagaaat tcaga t ccccaccgacgcccccgtgggtgt $t$ tggaa tccegcggt ggaagt gagtct caga

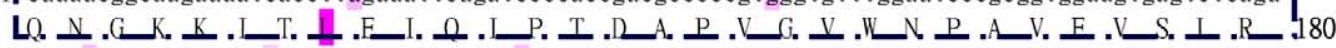

541 getacctcggacacgactcgacatctccaccgetccgacacgcatgtctacat tctct tcaatccetggaacaagcacgatgggacgtac

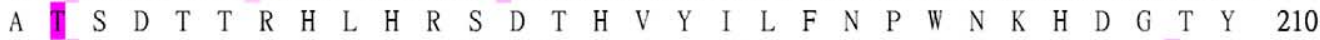

631 atgcaggacgaagagaaacgagacgaa tacgt tct ggctgacgt aggaaaga tct ggg tgggtaact accect accccacggecgeccc

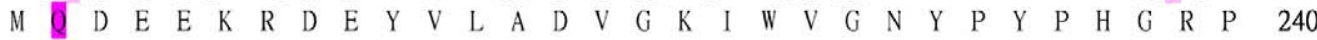

721 tgggtct tcgggcagt tcgacgacgcggtgctgccggcgagcgtgct gct gct cgagaagt cgggcgtccegccggagtctcgcggcgac

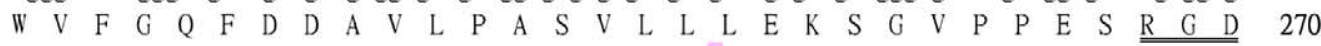

811 cccat ccgcgt gtccagagccat ct ccaaga tggt gaacagcaacgacgaccagggcgt gat cgt gggtcgt tgggacggcaagt acgaa $\begin{array}{llllllllllllllllllllllllllllllll}\text { P } & I & R & V & S & R & A & I & S & K & M & V & N & S & N & D & D & Q & G & V & I & V & G & R & W & D & G & K & Y & E & 300\end{array}$

901 gacgggaagtcccct cgtcgt ggt caggctccat caagat cctggaggaat acatcaaaagcaagcgece gtccget acggccagt gc $\begin{array}{lllllllllllllllllllllllllllllllll}\mathrm{D} & \mathrm{G} & \mathrm{K} & \mathrm{S} & \mathrm{P} & \mathrm{S} & \mathrm{S} & \mathrm{W} & \mathrm{S} & \mathrm{G} & \mathrm{S} & \mathrm{I} & \mathrm{K} & \mathrm{I} & \mathrm{L} & \mathrm{E} & \mathrm{E} & \mathrm{Y} & \mathrm{I} & \mathrm{K} & \mathrm{S} & \mathrm{K} & \mathrm{R} & \mathrm{P} & \mathrm{V} & \mathrm{R} & \mathrm{Y} & \mathrm{G} & \mathrm{Q} & \mathrm{C} & \mathbf{3} 30\end{array}$

991 tgggtct tcgccggggt tgtcaacacagtgtgtcgtgctctcggtctgcccagtcgagtggtcagcaact tcgcctcagcacacgacacc

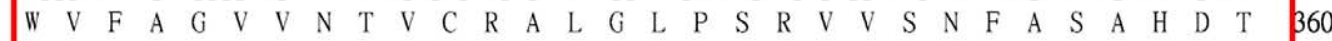

1081 aact tet ccct caccat tgacgaat acgt tgacgagaagggcgacgagat cgact cct cat accgcggtgct acccetggaggcctgtat $\begin{array}{llllllllllllllllllllllllllllllll}N & F & S & L & T & I & D & E & Y & V & D & E & K & G & D & E & I & D & S & S & Y & R & G & A & T & P & G & G & L & Y & 390\end{array}$

1171 gat tccatctggaact tccacgt $t$ tggaa tgacg tgtggatgat ccgacctgacctgecacagggt tacagcgget ggcaggt catcgac $\begin{array}{llllllllllllllllllllllllllllllll}D & S & I & W & N & F & \mathbf{H} & V & W & N & D & V & W & M & I & R & P & D & L & P & Q & G & Y & S & G & W & Q & V & I & D & 420\end{array}$

1261 gcaacg fcacaggaagcaagtgatggetcgtaccagtgegggccagcgtcccacgaggccatccgcagaggccaaatggaatacaagtac $\begin{array}{llllllllllllllllllllllllllllllll}\text { A } & T & P & Q & E & A & S & D & G & S & Y & Q & C & G & P & A & S & H & E & A & I & R & R & G & Q & M & E & Y & K & Y & 450\end{array}$

1351 gacgtgect tcgtgct ggccgaggt caacgetgacgtcgtgcact ggcagaaggacgat aaggcacaggacgggt tcaagaagct cacc

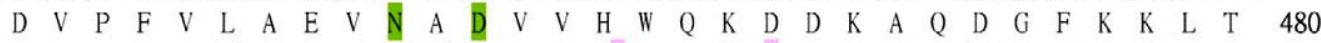

1441 acgaacaagaggagcgtcggccgccaggtgctgacgaagcaggt aggaccctcaagcgacaaggaggat atcacactggagtacaaaccg

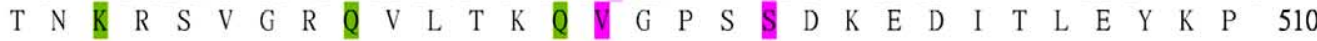

1531 aaggaagggacgacggccgagagagt cacgct act aacagctgcccgaaggaccegcgecgccagacacgcct tccgtctcatgtcccaa

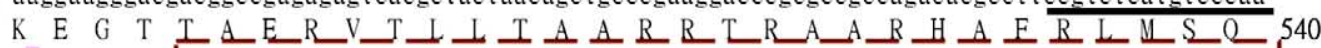

1621 gaagt aga tgadgt tgagt tcggcctcgaggacat cgagaaag gcccat cggcgaagggt tcaccgtgacgct caat tgcaagaacat $t$ $\left.\begin{array}{lllllllllllllllllllllllllllll}\hline & D & D & D\end{array}\right]$

1711 agcgaggccaagagaacggtgagtgtggtaatgaactgcaccagtatgtactacacaggcgeccecget taccegataaagcgecgtgag

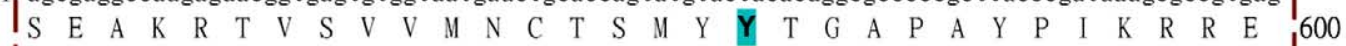

1801 ggagaaa t cgt tct cgaagt tggagaaaccaagaaca t gacca tggaag tgacgt acgg tgact act acgagaaact ggt cgaacacgcc

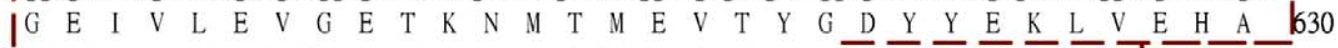

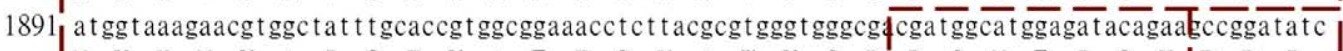

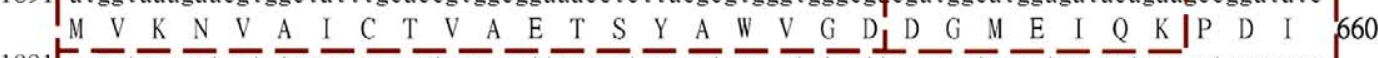

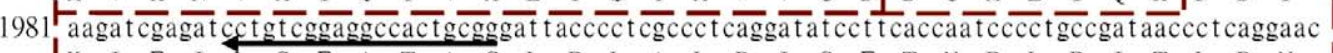

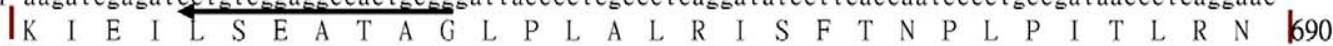

2071| tgcgagctggagg tggatggtcccggcatcctgcgccccaagactat accgatcagcaacgtgggecccagtgagaatatggtccatgag | $\begin{array}{lllllllllllllllllllllllllllllllll}I^{C} & E & L & E & V & D & G & P & G & I & L & R & P & K & T & I & P & I & S & N & V & G & P & S & E & N & M & V & H & E & P^{720}\end{array}$ 2161, a tgaaagtgt tcccaaagaacccaagcact gcacaat agt cgt gacct tcaact ccagccagct t acaacct tacggggtcaactcag

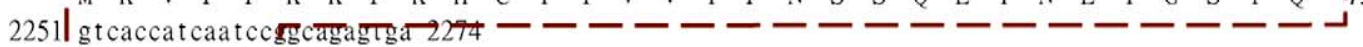
IV T I N P P I A E

Fig. 1. The open reading frame of shrimp transglutaminase II (STG II). Numbers in the left column and the right column indicate the numbers of nucleotides and amino acid residues, respectively. Nucleotides different from AF469484 are highlighted in light pink and the resultant residue 
with $50 \mathrm{mM} \mathrm{NaH} \mathrm{PO}_{4}, 300 \mathrm{mM} \mathrm{NaCl}$ and $5 \mathrm{mM}$ imidazole ( $\mathrm{pH}$ 8.0). Clear cell lysate was subjected to an Ni-NTA (Qiagen, USA) column, continually washed with $50 \mathrm{mM} \mathrm{NaH} \mathrm{PO}_{4}, 300 \mathrm{mM} \mathrm{NaCl}$ and $5 \mathrm{mM}$ imidazole $\left(\mathrm{pH}\right.$ 8.0) until the $\mathrm{OD}_{280}$ of the flowthrough was lower than 0.1 , and eluted with $50 \mathrm{mM} \mathrm{NaH} \mathrm{PO}_{4}, 300 \mathrm{mM} \mathrm{NaCl}$ and $250 \mathrm{mM}$ imidazole ( $\mathrm{pH}$ 8.0). For further assay, the eluted fractions containing rSTG II were dialyzed against $50 \mathrm{mM}$ Tris- $\mathrm{HCl}$ and $1 \mathrm{mM}$ ethylenediaminetetraacetate (EDTA) (pH 7.5) at $4{ }^{\circ} \mathrm{C}$ for $4 \mathrm{~h}$. The protein concentration was determined by the Bradford method [54], using bovine serum albumin as a standard. The purified rSTG II was stored at $4{ }^{\circ} \mathrm{C}$ for analysis within one week.

\subsection{Purification of shrimp clottable protein and preparation of shrimp haemocyte lysate}

The shrimp clottable protein $(\mathrm{CP})$ was purified as described by Yeh [5], with slight modification. Briefly, the shrimp plasma was dialyzed against the modified TE buffer $(50 \mathrm{mM}$ Tris- $\mathrm{HCl}$ and $1 \mathrm{mM}$ EDTA; pH 8.0) for $14 \mathrm{~h}$ at $4{ }^{\circ} \mathrm{C}$, subjected to DEAE cellulose (Sigma, USA) column pre-equilibrated with the modified TE buffer with $0.1 \mathrm{M} \mathrm{NaCl}$ and eluted with a step-wise gradient of $\mathrm{NaCl}$ at $4{ }^{\circ} \mathrm{C}$. For the DCA-incorporation assay and TEM observation, each fraction was dialyzed against the TE buffer with $0.1 \mathrm{M}$ $\mathrm{NaCl}$ at $4{ }^{\circ} \mathrm{C}$ overnight. The shrimp haemocyte lysate supernatant (HLS) was prepared following Sung's procedure [55]. Briefly, shrimp hemolymph was withdrawn using a syringe containing an anticoagulant as described in cDNA preparation and centrifuged at $700 \times g$ for $10 \mathrm{~min}$ to collect the haemocytes. The haemocytes were washed using anticoagulant, centrifuged again and then stored at $-20{ }^{\circ} \mathrm{C}$. The haemocytes obtained from $1 \mathrm{ml}$ of withdrawn hemolymph were lysed with $50 \mathrm{mM}$ Tris- $\mathrm{HCl}$ and $1 \mathrm{mM}$ EDTA (pH 7.5) and the protein concentration was determined by the Bradford method [54], using bovine serum albumin as a standard.

\subsection{Transglutaminase activity assay by dansylcadaverine incorporation}

Three microlitres of sample containing rSTG II $(110 \mu \mathrm{g} / \mathrm{ml})$ was pre-incubated for 5 min with $4 \mu \mathrm{l}$ of shrimp clottable protein $(\mathrm{CP}, 1.02 \mathrm{mg} / \mathrm{ml})$ in the presence of dansylcadaverine $(0.5 \mathrm{mM})$ and dithiothreitol (DTT, $1 \mathrm{mM}$ ). The dansylcadaverine incorporation reaction was initiated by adding $1 \mu \mathrm{l}$ of $\mathrm{CaCl}_{2}(1 \mathrm{M})$ and the mixture was incubated at room temperature. The reaction was stopped by adding an equal volume of SDS-PAGE sample buffer and boiling for $10 \mathrm{~min}$ and resolved by SDS-PAGE on $5 \%$ acrylamide gel.

\subsection{Clotting activity assay by TEM}

The DEAE purified CP is a mixture of monomers and polymers. The purified product was filtered with an ultrafiltration tube with a MWCO of $300 \mathrm{kDa}$ by the manufacturer's protocol (VivaScience, Germany). The rSTG II $(110 \mu \mathrm{g} / \mathrm{ml}, 10 \mu \mathrm{l})$ or the freshly prepared HLS (protein concentration $10 \mathrm{mg} / \mathrm{ml}$, $10 \mu \mathrm{l}$ ) was incubated with clottable protein (diluted to $255 \mu \mathrm{g} / \mathrm{ml}, 40 \mu \mathrm{l}$ ) or heated shrimp plasma (diluted tenfold to $9 \mathrm{mg} / \mathrm{ml}, 40 \mu \mathrm{l}$ ), and the clotting process was initiated by the addition of $\mathrm{CaCl}_{2}(1 \mathrm{M}, 1 \mu \mathrm{l})$. The clotting reaction was stopped by EDTA after 15 or $90 \mathrm{~s}$. Twenty microlitres of serial diluted reaction product was added onto a 200-mesh copper grid coated with formvar and carbon and stood for $5 \mathrm{~min}$ for the deposition of the cross-linked products. Excess sample solution was removed with filter paper. UA (Uranyl Acetate, Electron Microscopy Sciences, PA, USA) solution was added onto the sample-deposited grid and stood for 5-6 min as negative stain. After excess UA solution was removed with filter paper,

\footnotetext{
differences are highlighted in pink. The primer pair used in RT-PCR analysis for tissue distribution is indicated by arrows. The domains of STG II are organized serially as one N-terminal domain (dashed and dotted square, V54-R180), one catalytic core (solid square, V325-T422) and two C-terminal domains (dashed square, V545-D650 and P658-P755). The catalytic triads (CHD) of transglutaminase are labelled in red. Y-588, forming hydrogen bond with the catalytic $\mathrm{C}$ in the absence of calcium ions, is in light cyan. Residues that might be involved in calcium binding are highlighted in yellow (by sequence similarity with the crystal structure of human TG3, 1VJJ) and in green (by sequence similarity with the crystal structure of human Factor XIIIa, 1EVU). A putative ATP/GTP binding site motif A is underlined. Two cell attachment motifs RGD and KGD are doubly underlined.
} 
the preparations were analysed with a Zeiss 902 transmission electron microscope at an acceleration voltage of $80 \mathrm{kV}$.

\subsection{In vitro clotting assay}

To assess the role of shrimp TG in coagulation, the anticoagulant-plasma was heated at $55^{\circ} \mathrm{C}$ for $30 \mathrm{~min}$ to inactivate the endogenous STG released during hemolymph withdrawal or centrifugation. Samples containing STG (rSTG II [at least $110 \mu \mathrm{g} / \mathrm{ml}, 10 \mu \mathrm{l}$ ] or the freshly prepared HLS [protein concentration $10 \mathrm{mg} / \mathrm{ml}, 10 \mu \mathrm{l}])$ were added to $40 \mu \mathrm{l}$ of heated plasma and the in vitro clotting assay was initiated by adding $10 \mu \mathrm{l}$ of $\mathrm{CaCl}_{2}(1 \mathrm{M})$. The solutions were mixed thoroughly and incubated at room temperature. In 1-2 min, clot formation was observed for HLS catalysed clotting and in 10 to $60 \mathrm{~min}$ for rSTG II. The clot was gel-like and rated by eye as fluid (no clot) or stable clot. A 'stable clot' was defined as one which did not fall or slide when the tube was flicked. The clot was then heated at $55{ }^{\circ} \mathrm{C}$ for $1 \mathrm{~h}$ to determine the nature of cross-linking between backbones in the clot.

\section{Result}

\subsection{Sequence analysis of STG II}

The length of the STG II ORF is $2,274 \mathrm{bp}$. The deduced protein sequence contains 757 amino acid residues. The putative molecular weight $(\mathrm{Mw})$ is about $85 \mathrm{kD}$ and the putative $\mathrm{p} I$ is 5.48 . Using Motif Scan [50] to search protein patterns resulted sequentially in a transglutaminase $\mathrm{N}$-terminus domain (pos.:
54-180, E-value $\left.=3.6 \times 10^{-21}\right)$, a catalytic core domain (pos.: $325-422$, E-value $=9.3 \times 10^{-46}$ ) and two C-terminal domains (pos.: 545-650 and 658-755; $\mathrm{E}$-value $=6.1 \times 10^{-12}$ and $1.4 \times 10^{-13}$ respectively). The domains are organized as in a functional transglutaminase. The STG II ORF has 15 nucleotides, which differ from those of AF469484. The difference in nucleotide sequence resulted in six different amino acid residues. They are $\mathrm{F} 158 \rightarrow \mathrm{L}$, $\mathrm{N} 182 \rightarrow \mathrm{T}, \mathrm{P} 212 \rightarrow \mathrm{Q}, \mathrm{A} 495 \rightarrow \mathrm{V}, \mathrm{G} 499 \rightarrow \mathrm{S}$ and $\mathrm{G} 541 \rightarrow \mathrm{E}$. None of these replacements occurred in the predicted catalytic core domain. The catalytic triads of transglutaminase (C-330, H-397 and D-420) are fully conserved in the STG II. The STG II ORF sequence (AY771615) used in the present study and associated annotations is shown in Fig. 1. The Y-588 on the 1st C-terminal domain that covers the catalytic $\mathrm{C}$ by forming hydrogen bonds, in the absence of calcium activation [56], is conserved. One identified calcium-binding site of human Factor XIIIa (N-436, D-438, A-457, Q-485 and Q-490 [57]) is well conserved in the STG II (N-460, D-462, K-483, Q489 and Q-494). The conservation of a calciumbinding site suggests that STG II is also a calcium dependent transglutaminase. Moreover, a putative GTP/ATP binding motif A and two cell attachment motifs (RGD and KGD) were detected.

\subsection{Tissue distribution of STG II}

The RT-PCR result of the STG II is shown in Fig. 2. A low level of STG II expression was detected in the intestine, gills, heart, lymphoidal organ and subcuticular epithelium by the second round PCR. A modest level of STG II expression was detected in

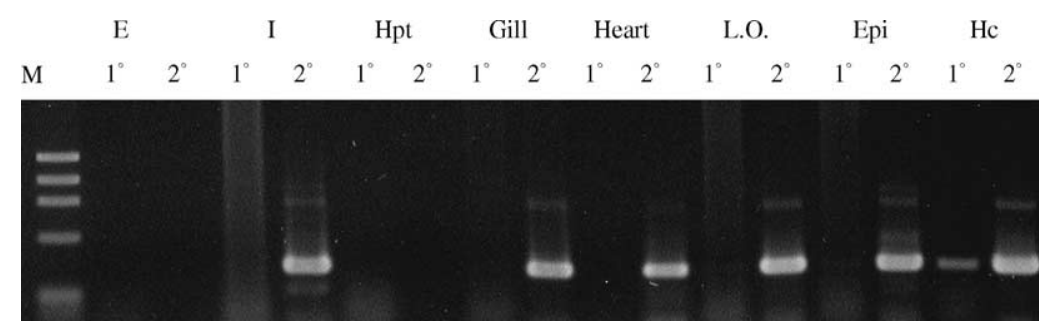

Fig. 2. STG II tissue distribution by RT-PCR analysis. Total RNA was extracted from the eyestalk, intestine, hepatopancreas, gills, heart, lymphoid organ, sub-cuticular epithelium and hemocytes (as shown from left to right). Primers specific to $P$. monodon TG II were designed to amplify a 400-bp fragment of shrimp TG II. No expression was detected in the eyestalk or hepatopancreas while significant expression was detected in hemocytes. $1^{\circ}$, the first round PCR; $2^{\circ}$, the second round PCR. 
haemocytes by the first round PCR. No expression was detected in the eyestalk and hepatopancreas. As for the lack of a detectable band in the eyestalk, which occurred also with STG I [38], it has been reported that DNA polymerase inhibitors are present in the eyestalk and always cause the amplification reaction to fail [58]. The most obvious difference in tissue distribution between STG I and STG II is that STG II is not expressed in the hepatopancreas.

\subsection{A maximum parsimony tree of STG II and other TGs of invertebrates}

Among the 270 protein sequences resulting from a PSI-BLAST search against the STG II, 11 representative invertebrate TG sequences were kept in our databases after elimination of all vertebrate TG sequences and incomplete fragments. The database contains TG sequences of two echinoderms (starfish and sea urchin) and seven arthropods (tiger shrimp, kuruma shrimp, crayfish, horseshoe crab, grasshopper, malaria mosquito and fruit fly). We constructed an information-rich tree by the maximum parsimony method with the branch-and-bound algorithm, in which the label of each sequence contains a symbol of taxonomy, the name of the organism, a length of the sequence and a GI number for convenience as a reference. In the maximum parsimony tree shown in Fig. 3, these TGs of invertebrates clustered into four groups (decapoda, horseshoe crab, echinodermata and insect). The bootstrap statistic ratio of each of the four groups is 100 , suggesting that the clustering is quite reliable. The most closely neighbouring cluster of the decapoda TG is the horseshoe crab TG, then the echinodermata TG and the insect TG. In the cluster of the decapoda TG, the STG II had the smallest genetic distance from kuruma shrimp TG, while the genetic distance between STG II and STG I is much larger than that between STG II and kuruma shrimp TG.

\subsection{The enzymatic activity of STG II}

The emitted fluorescence of dansylcadaverine (DCA), a fluorescent substrate for the assay of

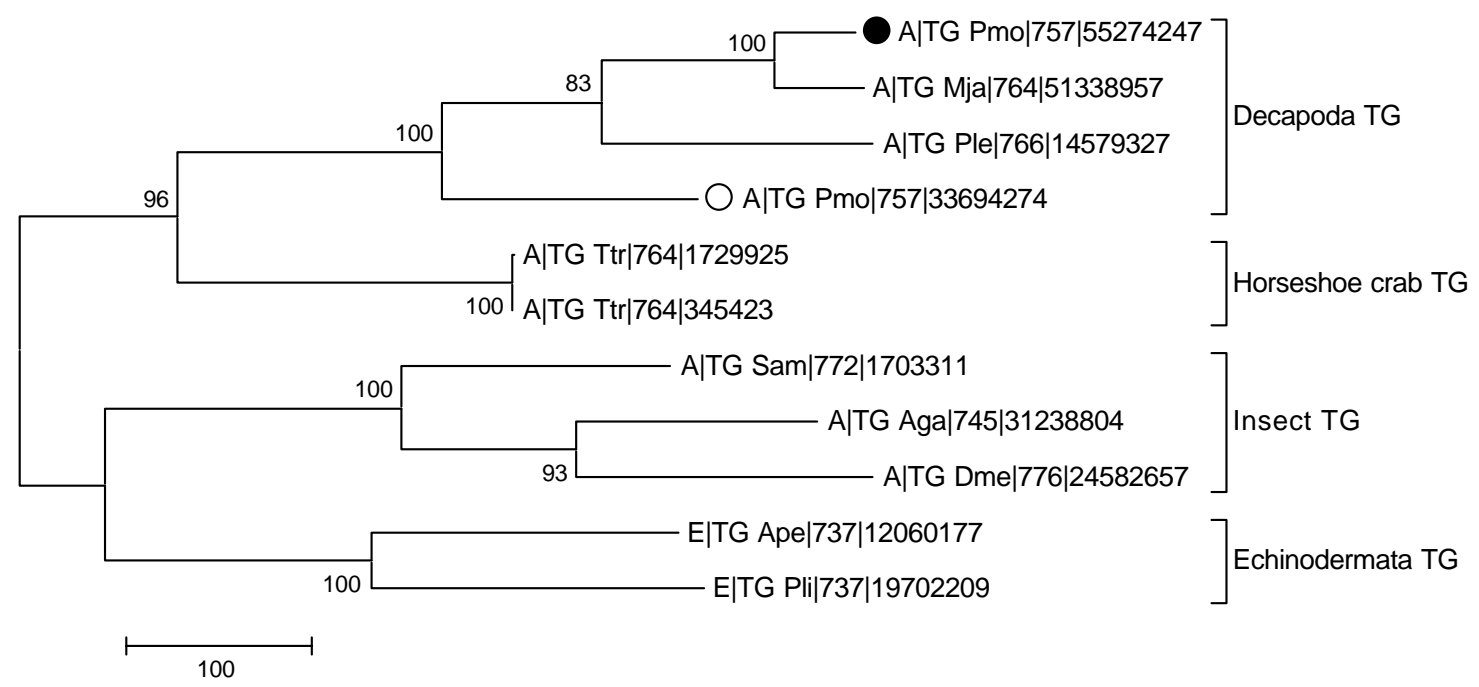

Fig. 3. A maximum parsimony tree of known invertebrate TGs. STG II and STG I are labelled with a closed circle $(\bullet)$ and an open circle $(O)$ respectively. The 11 TG sequences are clustered into four groups (Decapoda, Horseshoe crab, Echinodermata and Insect). All the sequences in the tree are labelled as [symbol of the taxonomy|TG organism|sequence length|GI number] in this information-rich tree. Symbol of the taxonomy: A for Arthropoda and E for Echinodermata. As for the abbreviation of organism, we have used the first letter of the genus name and the first two letters of the species name, i.e. Pmo for Penaeus monodon (tiger shrimp in this study); Mja for Marsupenaeus japonicus (kuruma shrimp); Ple for Pacifastacus leniusculus (crayfish); Ttr for Tachypleus tridentatus (horseshoe crab); Ape for Asterina pectinifera (sea star); Pli for Paracentrotus lividus (sea urchin); Sam for Schistocerca americana (grasshopper); Aga for Anopheles gambiae (malaria mosquito); and Dme for Drosophila melanogaster (fruit fly). The number at each branch represents the bootstrap (1000 replications) value. The tree was constructed by the maximum parsimony method with the branch-and-bound algorithm. The scale bar represents the genetic distance. 


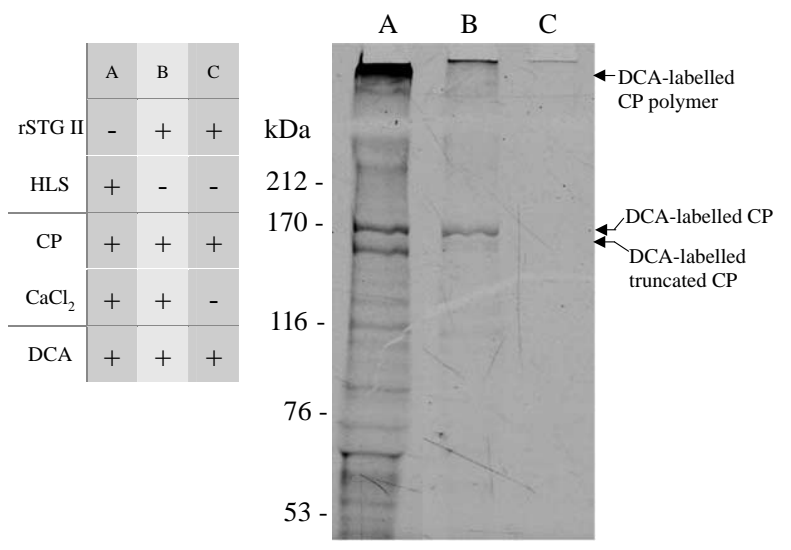

Fig. 4. Dansylcadaverine-incorporation assay of shrimp TG. The dansylcadaverine (DCA, $0.5 \mathrm{mM}$ ) was incorporated into $\mathrm{CP}$ by a calcium-dependent TG reaction. The incorporated DCA undergoes 'blue-shift' and emits blue light under UV excitation. For easier discrimination of DCA-labelled bands, the original picture was inversely processed. Freshly prepared HLS $(10 \mathrm{mg} / \mathrm{ml}, 3 \mu \mathrm{l})$ was used in the reaction of lane A while rSTG II $(110 \mu \mathrm{g} / \mathrm{ml}, 3 \mu \mathrm{l})$ was used in lanes $\mathrm{B}$ and $\mathrm{C}$ as the source of TG(s). CP polymer represents the polymerised form of $\mathrm{CP}$ (resulted from the release and reaction of hemocyte-derived STG(s) during hemolymph withdrawal and centrifugation). The two bands around $170 \mathrm{kDa}$ are $\mathrm{CP}$ and a truncated form of $\mathrm{CP}$ respectively [5]. (A) DCA was incorporated into $\mathrm{CP}, \mathrm{CP}$ polymer and unknown proteins by freshly prepared HLS. (B) DCA was incorporated into CP and CP polymer only by rSTG II. (C) In the absence of calcium, no DCA incorporation was observed. CP was not polymerized in the absence of rSTGII (unpublished data). The numbers on the left refer to the molecular weight from the HMW-SDS calibration kit (Pharmacia Biotech).

transamidating enzymes, is enhanced when DCA is incorporated into proteins. The emission wavelength is shifted to a shorter wavelength (blue shift). DCA has been used to trace the glutamine donor substrate of TG. As shown in Fig. 4, in a calcium dependent manner, the rSTG II was capable of incorporating DCA into CP as an endogenous haemocyte lysate TG. Both the endogenous STG(s) in HLS and rSTG II utilize CP as a glutamine donor substrate. STG II incorporated DCA into $\mathrm{CP}$ in a calcium dependent manner (as shown in lanes B and C in Fig. 4). The two bands around $170 \mathrm{kDa}$ in Fig. 4 are DCA-labelled CP and DCA-labelled truncated $\mathrm{CP}$ (due to degradation during frozen storage [5]). On the top is DCA-labelled, polymerised CP whose molecular weight is too large to enter the gel. Moreover, the HLS catalysed DCA-incorporation into bands other than $\mathrm{CP}$.

\subsection{TEM observation of CP backbones in coagulation product}

Polymerisation of $\mathrm{CP}$ is characteristic of the clotting process. Even though rSTG II was shown to be able to incorporate DCA into $\mathrm{CP}$, this is not equivalent to the polymerisation of CP by rSTG II. In the latter case, it is required that rSTG II recognize CP as a glutamine and lysine donor substrate simultaneously. To assay the clotting ability of rSTG II, we purified its clotting substrate, $\mathrm{CP}$, and removed large CP molecules polymerised during the process of hemolymph withdrawal and centrifugation by filtration through a concentration tube with a MWCO of $300 \mathrm{kDa}$. The unclotted CP is shown in Fig. 5(A). The individual $\mathrm{CP}$ is characterized as a globular protein with hexagonal symmetry. (A sharp projection is shown on the upper left in Fig. 5(C).) The length of each side of the hexagon is $5 \mathrm{~nm}$ and the diameter is approximately $10 \mathrm{~nm}$. The shape and size of tiger shrimp CP resemble those of the crayfish plasma clotting protein described by Hall et al. [6]. We identified the pattern in a near-native state (haemocyte lysate reacted with diluted plasma for $90 \mathrm{~s}$, shown in Fig. 5(C)) as elongation-dominated, with branching. When the rSTG II was introduced and reacted with CP for $15 \mathrm{~s}$, in the absence of the HLS endogenous TG, the isolated CPs were polymerised into elongated chains (Fig. 5(B)). In this case, branching was not observed yet.

\subsection{Characteristics of the clot}

Under the TEM, in the case of both rSTG II and HLS, CP was polymerised to form the backbones of the clot. Moreover, we would like to investigate the contribution of STG II in clot firmness. In the presence of sufficient rSTG II (final concentration $33 \mu \mathrm{g} / \mathrm{ml}$ ), the hemolymph was transformed into a stable clot as in the presence of HLS. In both cases, calcium chloride was used to initiate the reaction. We preliminarily examined the nature of cross-linking between the CP chains by simply heating the HLS catalysed hemolymph clot and found that its stability was not affected. However, the rSTG II catalysed clot was melted after being heated at $55{ }^{\circ} \mathrm{C}$ for $1 \mathrm{~h}$. The results are summarized in Table 1. 

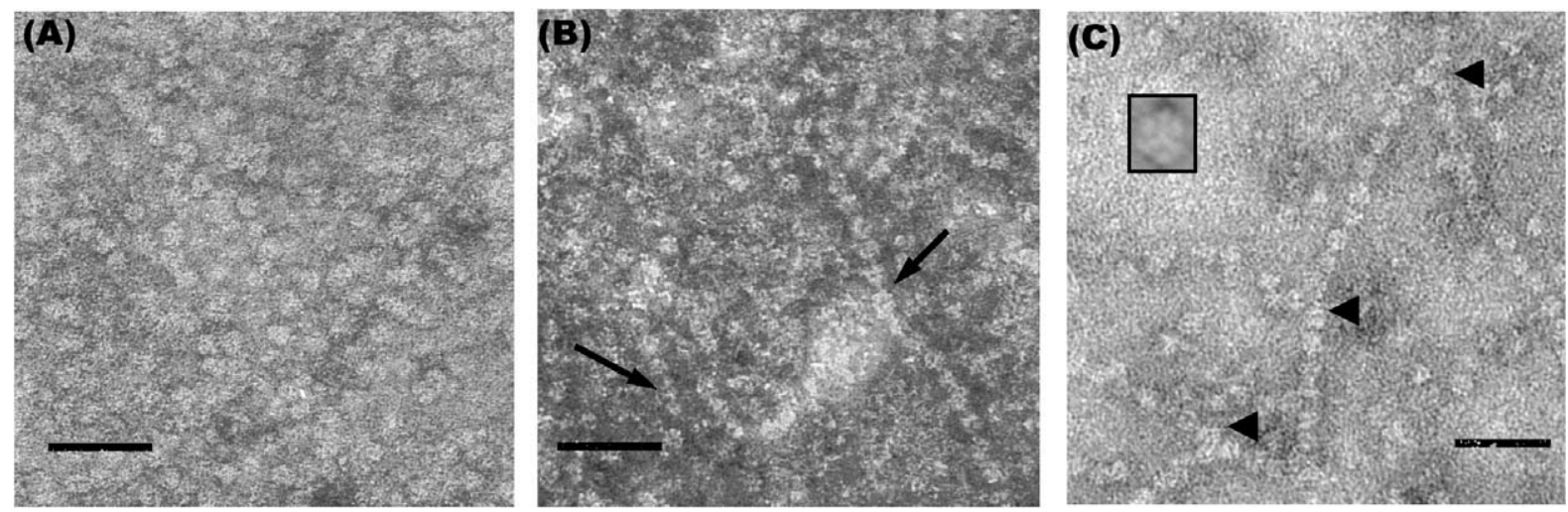

Fig. 5. Transmission electron microscopy observation of clot backbones polymerized by rSTG II. (A) After $90 \mathrm{~s}$, purified clottable proteins still remain isolated and detached from each other in the absence of any TG reaction. (B) Within $15 \mathrm{~s}$, the purified clottable proteins were polymerized into a long chain (as the arrow indicates) by rSTG II. (C) The clottable proteins in plasma were polymerized by hemocyte lysate supernatant (HLS). The arrowhead indicates the location where branching occurs. The reaction was initiated by adding calcium chloride and stopped at $90 \mathrm{~s}$ by adding excess EDTA. An amplified projection of clottable protein with hexagonal symmetry is shown in the square on the upper left. Bar $=50 \mathrm{~nm}$.

\section{Discussion}

We demonstrated that coagulation is one of the functions of shrimp TG and described its genetic relationship to other TGs. Coagulation is a conserved function necessary for animal survival. The diversity of coagulation systems among species may reflect the pressure and constraints encountered by individual species. TG, the most widely conserved protein, is well suited to investigate the coagulation system. Furthermore, as the redundancy of TG function and distribution remains a complex question in vertebrates, TG studies in invertebrates can provide an insight into TG evolution.

\subsection{Polymorphism of STG II}

The STG II (AY771615) clone used in this study was amplified from haemocyte cDNA with primers designed on AF469484. It has 99\% identity to AF469484 in its ORF sequence. The PCR amplified (AY771615) products contained 15 different nucleotides that resulted in six different amino acid residues (with comparison to AF469484). We do not consider this to be a mere PCR-prone mutation because the rate is much higher than the Taq-prone mutation rate (less than 1 per $10^{5}$ bp per duplication) [59]. Moreover, the variation did not scatter randomly as expected with Taq errors but avoided those conserved functional domain-encoding regions, and thus did not cause major changes in TG function. The variation should be treated as a naturally occurring polymorphism. Based on the limited differences between AY771615 and AF469484, we suggest they may be alleles of the STG II locus. Since the difference between sequences is limited ( $6 \mathrm{aa} / 757 \mathrm{aa}$ ) and the variation lies outside the catalytic core domain, it is possible that AF469484 product is also involved in coagulation.

Table 1

The mechanical and thermo-stable properties of clot formed by the catalyzation of purified rSTG II and HLS

\begin{tabular}{|c|c|c|c|}
\hline \multirow[t]{3}{*}{ Appearance of clot } & \multicolumn{3}{|l|}{ Source of TG } \\
\hline & \multicolumn{2}{|l|}{ rSTG II } & \multirow{2}{*}{$\begin{array}{l}\text { HLS (protein concentration } \\
10 \mathrm{mg} / \mathrm{ml} \text { ) }\end{array}$} \\
\hline & $\begin{array}{l}\text { Below the threshold concen- } \\
\text { tration }\end{array}$ & $\begin{array}{l}\text { Sufficient (final concentration } \\
33 \mu \mathrm{g} / \mathrm{ml} \text { ) }\end{array}$ & \\
\hline Before heat treatment & Fluid & Stable clot & Stable clot \\
\hline Afterheat treatment & Fluid & Melted as fluid & Stable clot \\
\hline
\end{tabular}

The appearance of clot was evaluated as fluid (no clot) or stable clot. A 'stable clot' was defined as one which did not fall or slide when the tube was flicked. The heating condition was set to be heated at $55^{\circ} \mathrm{C}$ for $1 \mathrm{~h}$. 
The polymorphism rate of the coding region of STG II $(15 / 2274,0.66 \%)$ is not significantly higher than the SNP (single nucleotide polymorphism) rate of human TG $1(15 / 2709,0.55 \%)$ and F. XIIIa $(14 / 3833,0.37 \%)$ coding regions [60]. In other words, compared with human TGs, the SNP rate of STG II seems not to reflect the shorter life cycle and the putative more stringent environmental stress encountered by marine invertebrates such as shrimps.

\subsection{Calcium interaction with STG II}

Eukaryotic TG is known as a calcium-activated enzyme [61]. Based on the concept of divergent evolution, we supposed the calcium binding site of shrimp TGII can be probed by sequence similarity to human F. XIIIa (1EVU) [57] or other type TG (e.g. human TG 3 (1VJJ) [62]). By this way, we identified two possible calcium-binding sites as indicated in Fig. 1. These two proposed calcium-binding sites are not at the same or nearby locations. This inconsistency suggests (1) the evolution of the calcium binding capacity of TG may be convergent, not divergent; (2) calcium interaction with TG might be much more flexible than was suggested by the static crystal structure data. TG lacks a typical calcium binding motif, such as the EF-hand structure of calmodulin. Also, the affinity of TG calcium-binding sites is low (excess EDTA easily blocked TG catalysis). It has been suggested that in TG, regions rich in negatively charged residues are potential calcium binding sites [63].

\subsection{More than one TG in invertebrates?}

In fruit flies and malaria mosquitoes, TG is encoded from a single locus in the genome. It is therefore reasonable to assume that these insect TGs must have multiple physiological functions and are ubiquitously expressed in all tissues. In previous discussions of invertebrate TGs [14], the single TG locus of the fruit fly has been taken as a standard case. However, in our analysis, two lines of evidence suggest that in that regard shrimps are different from insects. First, the expression of shrimp TGs is differential. STG II is mainly expressed in haemocytes but not in hepatopancreas, while STG I is ubiquitously expressed. The difference resembles that between human Factor XIII (mainly in haemocytes of myeloid lineage but not in liver) [64] and human tissue TG (ubiquitously expressed). Second, the genetic distance between STG II and STG I is greater than that between STG II and kuruma shrimp TG. Both pieces of evidence suggest that STG II and STG I are encoded on different loci. This finding would enrich the concept of TG evolution between invertebrates and vertebrates and reminds us that heterogeneous invertebrates should not be treated as a homogeneous whole. Moreover, whether the difference in the gene copy number is consistent with the different subclusters in the maximum parsimony tree is an interesting question to be answered by investigators dealing with other shrimps.

\subsection{The backbones of clot}

Except in the case of the horseshoe crab, our knowledge about the molecular mechanisms of invertebrate coagulation is quite limited. In the horseshoe crab, hemocytic TG catalyses the crosslinks between proxin and coagulin to transform the soft clot into a stable clot [34]. In this regard, proxin serves as the 'bridge' between coagulin by the catalyzation of TG (as shown in Fig. 6). In the shrimp, it is believed that the endogenous TG in haemocytes is sufficient to complete the coagulation reaction, converting the flowing hemolymph to a gellike stable clot $[5,6,41-43]$. However, the supporting data were established mainly on HLS and thus were not sufficient to demonstrate the role of transglutaminase alone in coagulation, especially in the light of the existence of more than one transglutaminase in the shrimp. This present study is the first demonstration in shrimps that the TG catalyses the polymerisation of $\mathrm{CP}$, forming at least the backbones of the clot.

As shown in Fig. 4, STG II could use CP and truncated CP as its substrate as HLS could. Yeh et al. demonstrated that the truncated form is due to frozen storage and truncated CP's clotting ability is not affected [5]. Under the TEM, clottable protein formed backbones of the clot by HLS or STG II. In the case of plasma reacted with HLS (Fig. 5(C)), unidirectional branches were observed, in a way similar to crayfish CP reacted with HLS demonstrated by Hall et al. [6]. However, in the case of shrimp CP reacted with STG II, 

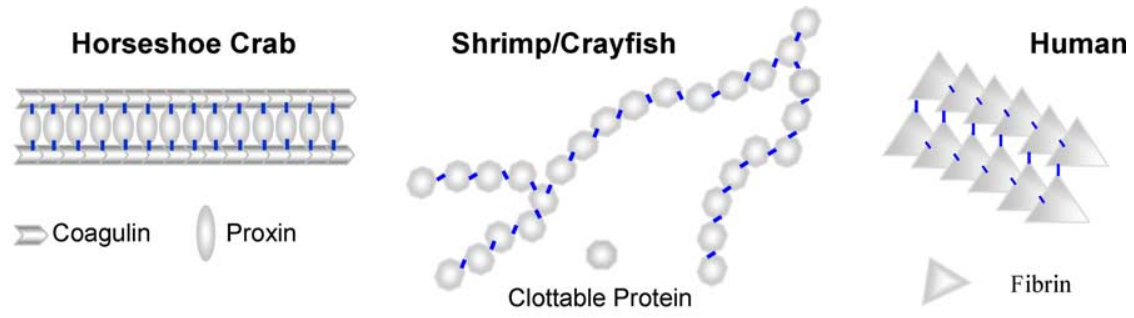

I Represents the cross-links catalysed by TG.

Fig. 6. A comparative diagram of TG-catalysed cross-links in coagulation products between horseshoe crab, shrimp/crayfish, and human. In horseshoe crabs, TG catalyses the cross-links between coagulin and proxin. In tiger shrimps in this study, we identified that at least TG catalyses intracross-links within the $\mathrm{CP}$ long chain. The $\mathrm{CP}$ long chain exhibits some flexibility. The branching in HLS-catalysed clot, as observed in tiger shrimp and crayfish, may contribute to the thermo-stability of the clotting products. In humans, TG (F. XIIIa) catalyses the cross-links between fibrins.

branches were not detected yet. The difference between Fig. 5(B) and (C), briefly no branching vs. branching, may be due to that lower activity of STG II (as shown in the DCA-incorporation assay in Fig. 4) or less reaction time prevented the development of longer chain and successful branching. Or it might be that STGs in HLS differentially catalyzed two types of linkage of CP. The possibility of other structural protein from plasma involved in backbone formation was excluded because that Hall et al. demonstrated the ability of branching in purified CP reacted with HLS [6].

Though the involvement of other structural protein involved in branching backbone formation was excluded as discussed in the previous paragraph, in Fig. 4, lane A, bands other than CP were incorporated with DCA by the endogenous TG in the haemocytes. This suggests the existence of other TG substrates in the hemolymph. These TG substrate candidates are worth identifying since they may also be components of a network building up the clot [34] or they may change their function in hemolymph derived innate immunity after post-translational modification by TG [65]. In the case of the fruit fly, more than one TG substrate in haemocyte and hemolymph was identified suggesting their potential role in hemolymph coagulation, but the primary structure of these substrates does not resemble any of the known proteins of shrimps [7]. In crayfish, alpha- 2 macroglobulin was also identified as a TG substrate [66]. An approach of TEM observation in coagulation analysis, however, may mask the presence and involvement of other substrates due to a limitation in the resolution of the negative staining method $(5 \mathrm{~nm}$ in diameter; i.e. protein with an $\mathrm{Mw}$ of about $200 \mathrm{kDa}$ ) [67] or the necessity of dilution when preparing samples to spread onto the grid.

\subsection{The stability of the clot}

In our preliminary heating test, the clotting product (plasma catalysed by HLS or STG II) was heated at $55^{\circ} \mathrm{C}$ for $1 \mathrm{~h}$ to investigate the nature of interbackbone connections. In plasma catalysed by HLS, the stability was not affected. The clot formed by rSTG II catalyzation was melted after being heated under the same conditions. Though the conditions were not optimised, this result implies that the covalent bridging between CP long chains enhanced the stability of HLS-catalysed clot. The covalent bridging may be mediated by branching as shown in Fig. 5(C) or/and by other unknown structural factors.

\section{6. $T G$ in the coagulation systems}

In Fig. 6, we tried to propose a diagram to illustrate the co-evolution between TG and TG substrates in the coagulation system. In the horseshoe crab, TG catalyses the cross-links between coagulin and proxin, making 'bridges' for coagulin [34]. In tiger shrimps in this study, we identified that TG catalyses cross-links within the $\mathrm{CP}$ long chain containing branching. In humans, TG (F. XIIIa) catalyses the the cross-links between fibrins.

These TG substrates, including proxin, coagulin, $\mathrm{CP}$ and fibrin, share little similarity in primary structures and this suggests no common origin in evolution. The finding in the fruit fly that has no identifiable orthologues of the haemostatic system of 
crustaceans, horseshoe crabs or humans except TG is consistent with the cases above [8]. The diversity of substrates reflects the flexibility of TG in a coagulation system, which might be shaped by the survival stress encountered.

\subsection{Potential active roles of clot in the innate immune system}

Besides viewing the clot as a physical barrier, we are curious about the interaction it may have with cellular components in the shrimp innate immune system, such as wound healing and extracellular matrix remodelling. It was demonstrated that transglutaminases could promote cell-matrix interaction through cross-linking of cell surface-associated fibronectin $[68,69]$ and non-covalent binding to integrins and fibronectin [70]. TG catalysed post-translational modification, RGD on shrimp TG and CP and $\mathrm{vW}$ factor on clottable protein may be important clues in exploring the role the clot plays in invertebrates. In addition to an enzymatic role, the protein band 4.2 (a TG homologue with the loss of catalytic activity) demonstrates TG's structural function as a major component of the cell membrane skeleton [28-32]. In STG II, the cell attachment motif (RGD/KGD) suggests that it is very likely to be involved in extracellular matrix remodelling and the recruitment of haemocytes.

\section{Acknowledgements}

We thank Prof. Yu-Chan Chao, Institute of Molecular Biology, Academia Sinica, for kindly providing the baculovirus transfer vector $\mathrm{pABhRpX}$. This work is financially supported by a grant (NSC932313-B-002-056) from the National Science Council, Republic of China.

\section{References}

[1] Theopold U, Schmidt O, Soderhall K, Dushay MS. Coagulation in arthropods: defence, wound closure and healing. Trends Immunol 2004;25:289-94.

[2] Tzou P, De Gregorio E, Lemaitre B. How Drosophila combats microbial infection: a model to study innate immunity and host-pathogen interactions. Curr Opin Microbiol 2002;5: 102-10.
[3] Iwanaga S, Kawabata S. Evolution and phylogeny of defense molecules associated with innate immunity in horseshoe crab. Front Biosci 1998;3:D973-D84.

[4] Tokunaga F, Yamada M, Miyata T, Ding YL, HiranagaKawabata M, Muta T, et al. Limulus hemocyte transglutaminase. Its purification and characterization, and identification of the intracellular substrates. J Biol Chem 1993;268:252-61.

[5] Yeh MS, Chen YL, Tsai IH. The hemolymph clottable proteins of tiger shrimp, Penaeus monodon, and related species. Comp Biochem Physiol B Biochem Mol Biol 1998; 121:169-76.

[6] Hall M, Wang R, van Antwerpen R, Sottrup-Jensen L, Soderhall K. The crayfish plasma clotting protein: a vitellogenin-related protein responsible for clot formation in crustacean blood. Proc Natl Acad Sci USA 1999;96: 1965-70.

[7] Karlsson C, Korayem AM, Scherfer C, Loseva O, Dushay MS, Theopold U: Proteomic analysis of the Drosophila larval hemolymph clot. J Biol Chem, 2004;279:52033-41.

[8] Theopold U, Li D, Fabbri M, Scherfer C, Schmidt O. The coagulation of insect hemolymph. Cell Mol Life Sci 2002;59: 363-72.

[9] Wang R, Liang Z, Hal M, Soderhall K. A transglutaminase involved in the coagulation system of the freshwater crayfish, Pacifastacus leniusculus. Tissue localisation and cDNA cloning. Fish Shellfish Immunol 2001;11:623-37.

[10] Folk JE, Finlayson JS. The epsilon-(gamma-glutamyl)lysine crosslink and the catalytic role of transglutaminases. Adv Protein Chem 1977;31:1-133.

[11] Folk JE. Transglutaminases. Annu Rev Biochem 1980;49: 517-31.

[12] Lorand L, Conrad SM. Transglutaminases. Mol Cell Biochem 1984;58:9-35.

[13] Greenberg CS, Birckbichler PJ, Rice RH. Transglutaminases: multifunctional cross-linking enzymes that stabilize tissues. FASEB J 1991;5:3071-7.

[14] Grenard P, Bates MK, Aeschlimann D. Evolution of transglutaminase genes: identification of a transglutaminase gene cluster on human chromosome 15q15. Structure of the gene encoding transglutaminase $X$ and a novel gene family member, transglutaminase Z. J Biol Chem 2001;276: 33066-78.

[15] Esposito C, Pucci P, Amoresano A, Marino G, Cozzolino A, Porta R. Transglutaminase from rat coagulating gland secretion. Post-translational modifications and activation by phosphatidic acids. J Biol Chem 1996;271:27416-23.

[16] Kim SY, Chung SI, Steinert PM. Highly active soluble processed forms of the transglutaminase 1 enzyme in epidermal keratinocytes. J Biol Chem 1995;270:18026-35.

[17] Steinert PM, Kim SY, Chung SI, Marekov LN. The transglutaminase 1 enzyme is variably acylated by myristate and palmitate during differentiation in epidermal keratinocytes. J Biol Chem 1996;271:26242-50.

[18] Kanaide H, Shainoff JR. Cross-linking of fibrinogen and fibrin by fibrin-stablizing factor (factor XIIIa). J Lab Clin Med 1975; 85:574-97. 
[19] Nielsen VG, Gurley Jr WQ, Burch TM. The impact of factor XIII on coagulation kinetics and clot strength determined by thrombelastography. Anesth Analg 2004;99:120-3.

[20] Wettstein P, Haeberli A, Stutz M, Rohner M, Corbetta C, Gabi K, et al. Decreased factor XIII availability for thrombin and early loss of clot firmness in patients with unexplained intraoperative bleeding. Anesth Analg 2004;99:1564-9.

[21] Koh D, Inohaya K, Imai Y, Kudo A. The novel medaka transglutaminase gene is expressed in developing yolk veins. Gene Expr Patterns 2004;4:263-6.

[22] Candi E, Melino G, Mei G, Tarcsa E, Chung SI, Marekov LN, et al. Biochemical, structural, and transglutaminase substrate properties of human loricrin, the major epidermal cornified cell envelope protein. J Biol Chem 1995;270:26382-90.

[23] Tarcsa E, Marekov LN, Andreoli J, Idler WW, Candi E, Chung SI, et al. The fate of trichohyalin. Sequential posttranslational modifications by peptidyl-arginine deiminase and transglutaminases. J Biol Chem 1997;272:27893-901.

[24] Achyuthan KE, Greenberg CS. Identification of a guanosine triphosphate-binding site on guinea pig liver transglutaminase. Role of GTP and calcium ions in modulating activity. J Biol Chem 1987;262:1901-6.

[25] Melino G, Piacentini M. 'Tissue' transglutaminase in cell death: a downstream or a multifunctional upstream effector? FEBS Lett 1998;430:59-63.

[26] Kang SK, Lee JY, Chung TW, Kim CH. Overexpression of transglutaminase 2 accelerates the erythroid differentiation of human chronic myelogenous leukemia K562 cell line through PI3K/Akt signaling pathway. FEBS Lett 2004;577:361-6.

[27] Ho KC, Quarmby VE, French FS, Wilson EM. Molecular cloning of rat prostate transglutaminase complementary DNA. The major androgen-regulated protein DP1 of rat dorsal prostate and coagulating gland. J Biol Chem 1992;267: 12660-7.

[28] Mandal D, Moitra PK, Basu J. Mapping of a spectrin-binding domain of human erythrocyte membrane protein 4.2. Biochem J 2002;364:841-7.

[29] Rybicki AC, Schwartz RS, Qiu JJ, Gilman JG. Molecular cloning of mouse erythrocyte protein 4.2: a membrane protein with strong homology with the transglutaminase supergene family. Mamm Genome 1994;5:438-45.

[30] Inoue T, Kanzaki A, Yawata A, Tsuji A, Ata K, Okamoto N, et al. Electron microscopic and physicobiochemical studies on disorganization of the cytoskeletal network and integral protein (band 3) in red cells of band 4.2 deficiency with a mutation (codon 142: GCT-> ACT). Int J Hematol 1994;59: 157-75.

[31] Risinger MA, Dotimas EM, Cohen CM. Human erythrocyte protein 4.2 , a high copy number membrane protein, is $\mathrm{N}$ myristylated. J Biol Chem 1992;267:5680-5.

[32] Najfeld V, Ballard SG, Menninger J, Ward DC, Bouhassira EE, Schwartz RS, et al. The gene for human erythrocyte protein 4.2 maps to chromosome $15 \mathrm{q} 15$. Am J Hum Genet 1992;50:71-5.

[33] Tokunaga F, Muta T, Iwanaga S, Ichinose A, Davie EW, Kuma K, et al. Limulus hemocyte transglutaminase. cDNA cloning, amino acid sequence, and tissue localization. J Biol Chem 1993;268:262-8.

[34] Osaki T, Okino N, Tokunaga F, Iwanaga S, Kawabata S. Proline-rich cell surface antigens of horseshoe crab hemocytes are substrates for protein cross-linking with a clotting protein coagulin. J Biol Chem 2002;277:40084-90.

[35] Singer MA, Hortsch M, Goodman CS, Bentley D. Annulin, a protein expressed at limb segment boundaries in the grasshopper embryo, is homologous to protein cross-linking transglutaminases. Dev Biol 1992;154:143-59.

[36] Sugino H, Terakawa Y, Yamasaki A, Nakamura K, Higuchi Y, Matsubara J, et al. Molecular characterization of a novel nuclear transglutaminase that is expressed during starfish embryogenesis. Eur J Biochem 2002;269: 1957-67.

[37] Adams MD, Celniker SE, Holt RA, Evans CA, Gocayne JD, Amanatides PG, et al. The genome sequence of Drosophila melanogaster. Science 2000;287:2185-95.

[38] Huang CC, Sritunyalucksana K, Soderhall K, Song YL. Molecular cloning and characterization of tiger shrimp (Penaeus monodon) transglutaminase. Dev Comp Immunol 2004;28:279-94.

[39] Holt RA, Subramanian GM, Halpern A, Sutton GG, Charlab R, Nusskern DR, et al. The genome sequence of the malaria mosquito Anopheles gambiae. Science 2002;298: 129-49.

[40] Fuller GM, Doolittle RF. Studies of invertebrate fibrinogen. II. Transformation of lobster fibrinogen into fibrin. Biochemistry 1971;10:1311-5.

[41] Martin Garry G, Hose Jo Ellen, Omori Sidne, Chong Celeste, Hoodbhoy Tanya, McKrell Nancy. Localization and roles of coagulogen and transglutaminase in hemolymph coagulation in decapod crustaceans. Comp Biochem Physiol 1991;100B: 517-22.

[42] Omori Sidne A, Martin Gary G, Hose Jo Ellen. Morphology of hemocyte lysis and clotting in the ridge back prawn, Sicyonia ingentis. Cell Tissue Res 1989;255:117-23.

[43] Hose Jo Ellen, Martin Gary G, Grenard Alison Sue. A decapod hemocyte classfication scheme integrating morphology, cytochemistry and function. Biol Bull 1990;178:33-45.

[44] Iwanaga S, Kawabata S, Muta T. New types of clotting factors and defense molecules found in horseshoe crab hemolymph: their structures and functions. J Biochem (Tokyo) 1998;123: 1-15.

[45] Muta T, Iwanaga S. The role of hemolymph coagulation in innate immunity. Curr Opin Immunol 1996;8:41-7.

[46] Muta T, Iwanaga S. Clotting and immune defense in Limulidae. Prog Mol Subcell Biol 1996;15:154-89.

[47] Iwanaga S. The limulus clotting reaction. Curr Opin Immunol 1993;5:74-82.

[48] Iwanaga S, Miyata T, Tokunaga F, Muta T. Molecular mechanism of hemolymph clotting system in Limulus. Thromb Res 1992;68:1-32.

[49] Song YL, Yu CI, Lien TW, Huang CC, Lin MN. Haemolymph parameters of Pacific white shrimp (Litopenaeus vannamei) infected with taura syndrome virus. Fish Shellfish Immunol 2003;14:317-31. 
[50] Falquet L, Pagni M, Bucher P, Hulo N, Sigrist CJ, Hofmann K, et al. The PROSITE database, its status in 2002. Nucleic Acids Res 2002;30:235-8.

[51] Altschul SF, Madden TL, Schaffer AA, Zhang J, Zhang Z, Miller W, et al. Gapped BLAST and PSI-BLAST: a new generation of protein database search programs. Nucleic Acids Res 1997;25:3389-402.

[52] Thompson JD, Gibson TJ, Plewniak F, Jeanmougin F, Higgins DG. The ClustalX windows interface: flexible strategies for multiple sequence alignment aided by quality analysis tools. Nucleic Acids Res 1997;25:4876-82.

[53] Kumar S, Tamura K, Jakobsen IB, Nei M. MEGA2: molecular evolutionary genetics analysis software. Bioinformatics 2001; 17:1244-5.

[54] Bradford MMA. rapid and sensitive method for the quantitation of microgram quantities of protein utilizing the principle of protein-dye binding. Anal Biochem 1976;72:248-54.

[55] Sung HH, Chang HJ, Her CH, Chang JC, Song YL. Phenoloxidase activity of hemocytes derived from Penaeus monodon and Macrobrachium rosenbergii. J Invertebr Pathol 1998;71:26-33.

[56] Noguchi K, Ishikawa K, Yokoyama K, Ohtsuka T, Nio N, Suzuki E. Crystal structure of red sea bream transglutaminase. J Biol Chem 2001;276:12055-9.

[57] Fox BA, Yee VC, Pedersen LC, Le T I, Bishop PD, Stenkamp RE, et al. Identification of the calcium binding site and a novel ytterbium site in blood coagulation factor XIII by X-ray crystallography. J Biol Chem 1999;274:4917-23.

[58] Lo CF, Ho CH, Chen CH, Liu KF, Chiu YL, Yeh PY, et al. Detection and tissue tropism of white spot syndrome baculovirus (WSBV) in captured brooders of Penaeus monodon with a special emphasis on reproductive organs. Diseases of Aquatic Organisms 1997;53-72.

[59] Eckert KA, Kunkel TA. High fidelity DNA synthesis by the Thermus aquaticus DNA polymerase. Nucleic Acids Res 1990;18:3739-44.

[60] Sherry ST, Ward MH, Kholodov M, Baker J, Phan L, Smigielski EM, et al. dbSNP: the NCBI database of genetic variation. Nucleic Acids Res 2001;29:308-11.
[61] Folk JE, Cole PW, Mullooly JP. Mechanism of action of guinea pig liver transglutaminase. 3. The metal-dependent hydrolysis of p-nitrophenyl acetate; further observations on the role of metal in enzyme activation. J Biol Chem 1967;242: 2615-21.

[62] Ahvazi B, Boeshans KM, Idler W, Baxa U, Steinert PM. Roles of calcium ions in the activation and activity of the transglutaminase 3 enzyme. J Biol Chem 2003;278:23834-41.

[63] Yee VC, Le T I, Bishop PD, Pedersen LC, Stenkamp RE, Teller DC. Structure and function studies of factor XIIIa by Xray crystallography. Semin Thromb Hemost 1996;22:377-84.

[64] Adany R. Intracellular factor XIII: cellular distribution of factor XIII subunit a in humans. Semin Thromb Hemost 1996; 22:399-408.

[65] Nishimura T, Horino K, Nishiura H, Shibuya Y, Hiraoka T, Tanase S, et al. Apoptotic cells of an epithelial cell line, AsPC1 , release monocyte chemotactic S19 ribosomal protein dimer. J Biochem (Tokyo) 2001;129:445-54.

[66] Hall Martin, Soderhall Kenneth. Crayfish alpha 2-macroglobulin as a substrate for transglutaminases. Comp Biochem Physiol Part B: Biochem Mol Biol 1994;108: 65-72.

[67] Spiess Eberhard, Zimmermann Hans-Peter, Lunsdorf Heinrich. Negative staining of protein molecules and filaments. In: Sommerville J, Scheer U, editors. Electron microscopy in molecular biology. Oxford, Washington DC: IRL Press; 1987. p. 147-66.

[68] Corbett SA, Lee L, Wilson CL, Schwarzbauer JE. Covalent cross-linking of fibronectin to fibrin is required for maximal cell adhesion to a fibronectin-fibrin matrix. J Biol Chem 1997; 272:24999-5005.

[69] Gaudry CA, Verderio E, Aeschlimann D, Cox A, Smith C, Griffin M. Cell surface localization of tissue transglutaminase is dependent on a fibronectin-binding site in its $\mathrm{N}$-terminal beta-sandwich domain. J Biol Chem 1999;274:30707-14.

[70] Gaudry CA, Verderio E, Jones RA, Smith C, Griffin M. Tissue transglutaminase is an important player at the surface of human endothelial cells: evidence for its externalization and its colocalization with the beta(1) integrin. Exp Cell Res 1999; 252:104-13. 